\title{
Peripartum cardiomyopathy management-multidisciplinary approach 2011-2013 at Care Institute of Medical Sciences
}

\author{
Pratibha Devabhaktuni $^{1}$, Sridevi Chennapragada ${ }^{1}$, Sushma Manchala $^{2}$, \\ Rajeev Menon ${ }^{1}$, Neelkanth Patil ${ }^{1}$, Somaraju Bhupatiraju ${ }^{1}$
}

\begin{abstract}
${ }^{1}$ Department of Cardiology, Care Institute of Medical Sciences, Hyderabad, Telangana, India
${ }^{2}$ Department of Obstetrics and Gynaecology, Care Institute, Hyderabad, Telangana, India
\end{abstract}

Received: 19 October 2020

Revised: 12 November 2020

Accepted: 13 November 2020

\section{*Correspondence: \\ Dr. Pratibha Devabhaktuni, \\ E-mail:dpdnk@yahoo.com}

Copyright: () the author(s), publisher and licensee Medip Academy. This is an open-access article distributed under the terms of the Creative Commons Attribution Non-Commercial License, which permits unrestricted non-commercial use, distribution, and reproduction in any medium, provided the original work is properly cited.

\section{ABSTRACT}

Background: Peripartum cardiomyopathy (PPCM) is one of the rare causes of heart failure in pregnant women. It occurs in late pregnancy or up to 5 months post-partum. It is associated with high mortality and morbidity but with chances of full recovery. This paper discusses the treatment of peripartum cardiomyopathy, Peripartum cardiomyopathy management -multidisciplinary approach. 2011-2013 at CIMS.

Methods: This is an observational study conducted at CARE institute of medical sciences, CIMS, during 2011-2013 years. Women fulfilling the criteria for the diagnosis of PPCM were included in the study. In this study we have analysed the obstetric intervention, the duration of ICU stay, hospital stay, maternal and perinatal outcomes. The cardiac drugs to manage each individual case suited to her condition have been mentioned.

Results: Six cases were diagnosed to have PPCM in pregnancy when there was sudden onset of shortness of breath, cough, and palpitations. Four cases had history of PPCM in previous pregnancies and were managed in the current pregnancy. One rare case had features of cardiomyopathy seen in early gestational period, during the first trimester at eight weeks, when she was treated for ectopic gestation. Patients were managed by pregnancy cardiac team. There was no case of maternal mortality.

Conclusions: PPCM is a rare condition. It requires a high index of suspicion and awareness among primary care givers for early diagnosis and prompt management. A pregnancy cardiac team approach benefits this subset of patients. Delayed time of presentation, LVEF and dilated ventricle are factors determining recovery.

Keywords: Peripartum cardiomyopathy, Pregnancy, Heart disease, Cardiomyopathy, Pregnancy cardiac team

\section{INTRODUCTION}

Peripartum cardiomyopathy (PPCM) is one of the rare causes of heart failure in pregnant women. It occurs in late pregnancy or up to 5 months post-partum. It is associated with high mortality and morbidity but with chances of full recovery. The disease progresses rapidly but recovery rates are more if diagnosed early. It was described by Virchow and others but seminal publications by Damakis and Rahmatoola have brought it into notice. ${ }^{1,2}$ There is a significant variability in incidence depending on time of study, region, ethnicity and dietary habits. The risk factors are multi para, multiple pregnancies, hypertension, prolonged tocolytic therapy, family history and preeclampsia. ${ }^{3}$

Older studies estimate prevalence of PPCM in the United States at 1 in 4,000 live births, more recent studies place this estimate closer to one in $2,000 .{ }^{4} \mathrm{PPCM}$ is endemic in 
Haiti and parts of Africa, and race remains a major risk factor for its development..$^{5-7}$ The data from euro observational registry which is still enrolling patients is awaited. Few case series are reported from India and the incidence in this part of world remains under reported. In one of a retrospective study data show PPCM was more common in African Americans (43.9\%) as compared with white $(40.8 \%)$, Hispanic $(8.7 \%)$ and Asian $(2.7 \%)$ women. ${ }^{8}$ Women in late pregnancy and early post-partum period complain of pedal edema, shortness of breath and fatigue. There is a significant overlap of symptoms with women of normal pregnancy. Obesity and hypertension also can present with breathlessness. PPCM is a diagnosis of exclusion. Women with these complaints need to undergo ECG and echocardiogram and bio markers like brain natriuretic peptide and troponin to rule out underlying heart disease and rule in a diagnosis of peri partum cardiomyopathy. Early diagnosis of PPCM improves chances of early recovery and results in better prognosis. Presentations later in post-partum period and those women who have dilated left ventricle lead to long term poor prognosis and need for advanced therapies. Management of patients by multiple specialties like GP, gynecologists and pregnancy cardiac team leads to improved outcomes. Table 1 shows the definitions given for PPCM by different committees. ${ }^{1,9,10}$

Table 1: Definitions given for PPCM by various committees.

\begin{tabular}{|c|c|}
\hline Author & Criteria/definition \\
\hline Damakis et al & $\begin{array}{l}\text { Heart failure develops in the last month of pregnancy or } \\
\text { within } 5 \text { months of delivery. Heart pumping function is } \\
\text { reduced, with an ejection fraction (EF) less than } 45 \% \\
\text { (typically measured by an echocardiogram). No other } \\
\text { underlying structural heart disease is present as a cause for } \\
\text { heart failure. fS is }<30 \% \text { LVEED }>2.7 \mathrm{~cm}^{2}(1)\end{array}$ \\
\hline $\begin{array}{l}\text { European society of cardiology on the Classification } \\
\text { of Cardiomyopathies }\end{array}$ & $\begin{array}{l}\text { A non-familial, non-genetic form of dilated } \\
\text { cardiomyopathy associated with pregnancy. }\end{array}$ \\
\hline $\begin{array}{l}\text { AHA scientific statement on contemporary } \\
\text { definitions and classifications of the } \\
\text { cardiomyopathies }\end{array}$ & $\begin{array}{l}\text { A rare and dilated acquired primary cardiomyopathy } \\
\text { associated LV Dysfunction and heart failure. }\end{array}$ \\
\hline $\begin{array}{l}\text { Workshop held by the National heart lung Blood } \\
\text { institute and the office of RARE Disease. }{ }^{9}\end{array}$ & $\begin{array}{l}\text { The development of heart failure in the last month of } \\
\text { pregnancy or within } 5 \text { months post-partum }\end{array}$ \\
\hline $\begin{array}{l}\text { Heart failure association of the European society of } \\
\text { Cardiology working group on PPCM } 2010 .^{10}\end{array}$ & $\begin{array}{l}\text { The absence of an identifiable cause of heart failure 1) the } \\
\text { absence of recognizable heart disease to last month of } \\
\text { pregnancy 2) LV systolic dysfunction demonstrated by } \\
\text { classical echocardiographic criteria, The latter may be } \\
\text { characterized as an LV ejection fraction }<45 \% \text {, fractional } \\
\text { shortening of }<30 \% \text {, or both, with or without an LV end - } \\
\text { diastolic dimension }>2.7 \mathrm{~cm} / \mathrm{m}^{2} \text { body surface area } 3 \text { ) The } \\
\text { left ventricle may not be dilated but the ejection fraction is } \\
\text { nearly always reduced below } 45 \% \text { (10). }\end{array}$ \\
\hline
\end{tabular}

\section{METHODS}

This is an observational study conducted at CARE institute of medical sciences, CIMS, during 2011-2013 years.

Inclusion criteria were women in late pregnancy and early post-partum period complain of pedal edema, shortness of breath and fatigue. There is a significant overlap of symptoms with women of normal pregnancy. Obesity and hypertension also can present with breathlessness. PPCM is a diagnosis of exclusion. Women with these complaints need to undergo ECG and echocardiogram and bio markers like brain natriuretic peptide and troponin to rule out underlying heart disease and rule in a diagnosis of peripartum cardiomyopathy.
The absence of an identifiable cause of heart failure. The absence of recognizable heart disease to last month of pregnancy.

LV systolic dysfunction demonstrated by classical echocardiographic criteria, the latter may be characterized as an LV ejection fraction $<45 \%$, fractional shortening of $<30 \%$, or both, with or without an LV end -diastolic dimension $>2.7 \mathrm{~cm} / \mathrm{m}^{2}$ body surface area.

The left ventricle may not be dilated but the ejection fraction is nearly always reduced below $45 \%$. A nonfamilial, non-genetic form of dilated cardiomyopathy associated with pregnancy. Heart failure develops in the last month of pregnancy or within 5 months of delivery. Heart pumping function is reduced, with an ejection fraction (EF) less than $45 \%$ (typically measured by an echocardiogram). 
Women fulfilling the above criteria were included in the study.

Women admitted with preeclampsia, would have renal function tests, liver function tests, LDH, CBP with platelet count, to detect HELLP syndrome (hemolysis, elevated liver enjymes, low platelet count).

When needed coagulation studies would be done. This is in addition to the regular antenatal profile. These women are categorized as critical cases in ER, emergency room, an immediate consultation of cardiologist, intensivist, anaesthetist would be sought in addition to the obstetrician within a couple of minutes of admission.

A detailed history of obstetric record would be sought, a perusal of all the investigations done thus far from referral centres would be documented. A consent for surgical intervention, if needed would be taken. Availability of blood products would be verified. Attendants counseling would be done to explain the critical nature of the condition.

The management instituted would consider the fetal salvage of utmost importance and tests would be done, a scan for fetal state. A paediatrician would be called at the time of delivery to attend to the fetus. The woman would be managed as an obstetric emergency. At the time of discharge a repeat 2D ECHO (electro cardiography) would be performed, advice regarding further follow up informed.

In this study we have analysed the obstetric intervention, the duration of ICU stay, hospital stay, maternal and perinatal outcomes. The cardiac drugs to manage each individual case suited to her condition have been mentioned. Ethics committee approval was taken for the study.

\section{RESULTS}

\section{Age of the women with PPCM}

The primies who were included in our study were young with age range of 21 to 27 years. The mean age of the patients was 24.7 years. (Table 2) clinical data in 11 patients.

\section{Status of gravida, parity and pregnancy}

Primies were six, second gravida were two and third gravida were three.

\section{Presenting complaints}

In our series $7(63.6 \%)$ presented with heart failure, 5 $(45 \%)$ with exertional breathlessness, 2 (18\%) with pedal oedema and 1 (9\%) with syncope. Nearly half (54\%) patients had sinus tachycardia at presentation and one patient had PVCs. Table 3 shows cardiac features of the 11 patients.

Table 2: Clinical data in 11 patients.

\begin{tabular}{|ll|}
\hline Characteristics & \\
\hline Total number of patients & 11 \\
\hline Mean age & 24.7 \\
\hline Mean parity & 1.09 \\
\hline Time of presentation & $\begin{array}{l}9 \text { weeks }-6 \text { months } \\
\text { post-partum }\end{array}$ \\
\hline Primi & 6 \\
\hline Previous PPCM & 4 \\
\hline Hypertension & 4 \\
\hline HELPP syndrome & 1 \\
\hline Vaginal delivery & 1 \\
\hline Abortion & 1 \\
ectopic pregnancy & 1 \\
\hline LSCS & 8 \\
\hline
\end{tabular}

Table 3: Cardiac features of the 11 patients.

\begin{tabular}{|ll|}
\hline NYHA class & Number of patients \\
\hline $\mathbf{4}$ & 5 \\
\hline $\mathbf{3}$ & 1 \\
\hline $\mathbf{2}$ & 5 \\
\hline SOB & 5 \\
\hline Edema & 2 \\
\hline Syncope & 1 \\
\hline Shock & 1 \\
\hline Sinus tachycardia & 6 \\
\hline PVC & 1 \\
\hline No cardiac symptoms & 4 \\
\hline
\end{tabular}

\section{Onset of PPCM in relation to pregnancy and gestational period}

In the group of women with PPCM in relation to the current pregnancy, three had PPCM at 37, 38 and 39 weeks of pregnancy. One woman developed symptoms on the second postpartum day, one on the sixth day. Another had manifestation in the sixth postpartum week.

Among the four women who developed PPCM in the previous pregnancy, as per the history, one developed PPCM at term gestation, one, four months after delivery and two in the postpartum period, with in the first week of delivery.

Out of 10 cases, PPCM was diagnosed prior to delivery in 4 women and in 6 the manifestation was in the postpartum period. Table 4 clinical profile PPCM during pregnancy -6 cases,

Table 5 clinical profile of women with PPCM in previous pregnancy four cases. 
Association of PPCM with Preeclampsia, imminent eclampsia and HELLP syndrome: Out of six cases diagnosed to have PPCM in the current pregnancy, four had severe preeclampsia, and in one severe preeclampsia and HELLP syndrome.

Table 4: Clinical profile PPCM during pregnancy-6 cases.

\begin{tabular}{|c|c|c|c|c|c|c|c|c|c|}
\hline $\begin{array}{l}\text { S. } \\
\text { no. }\end{array}$ & $\begin{array}{l}\text { Age } \\
\text { (yrs) }\end{array}$ & $\begin{array}{l}\text { REFE } \\
\text { RRED }\end{array}$ & ОВН & $\begin{array}{l}\text { Time of onset } \\
\text { of PPCM }\end{array}$ & GHTN & Echo & Lscs/vd & Drugs & $\begin{array}{l}\text { Hospital } \\
\text { stay }\end{array}$ \\
\hline 1 & 23 & + & P111 & $6^{\text {th }}$ pod & + & $\begin{array}{l}\text { Ef- } \\
35 \%\end{array}$ & $\begin{array}{l}\text { LSCS } \\
\text { (CPD) }\end{array}$ & $\begin{array}{l}\text { Metoprolol } \\
\text { Amlodepine } \\
\text { Telmisartan } \\
\text { Ivabradine }\end{array}$ & $11(4)$ \\
\hline 2 & 26 & + & $\begin{array}{l}\text { Primi-39 } \\
\text { wks }\end{array}$ & 39 wks & + & $\begin{array}{l}\text { Ef- } \\
42 \%\end{array}$ & $\begin{array}{l}\text { EM- } \\
\text { LSCS }\end{array}$ & $\begin{array}{l}\text { Labetalol } \\
\text { Digoxin } \\
\text { Aldactone } \\
\text { Frusemide }\end{array}$ & $6(5)$ \\
\hline 3 & 25 & + & $\begin{array}{l}\text { Primi-38 } \\
\text { wks }\end{array}$ & 38 wks & + & $\begin{array}{l}\text { Ef- } \\
25 \%\end{array}$ & $\begin{array}{l}\text { EM- } \\
\text { LSCS }\end{array}$ & $\begin{array}{l}\text { Methyldopa } \\
\text { Amlodepine } \\
\text { ivabradine } \\
\text { Frusemide }\end{array}$ & $10(8)$ \\
\hline 4 & 27 & & $\begin{array}{l}\text { G2p 111- } \\
37 \text { wks }\end{array}$ & $2^{\text {nd }}$ pod & + & $\begin{array}{l}\text { Ef- } \\
43 \% \\
\end{array}$ & $\begin{array}{l}\text { EM- } \\
\text { LSCS }\end{array}$ & $\begin{array}{l}\text { Labetalol } \\
\text { Ivabradin }\end{array}$ & 4 \\
\hline 5 & 21 & + & $\begin{array}{l}\text { Primi-37 } \\
\text { wks }\end{array}$ & At 36 wks & & $\begin{array}{l}\text { Ef- } \\
25 \%\end{array}$ & LSCS & $\begin{array}{l}\text { Betaloc } \\
\text { Frusemide } \\
\text { Telmasartun }\end{array}$ & $8(5)$ \\
\hline 6 & 21 & + & Pili & $\begin{array}{l}6^{\text {th }} \text { post- } \\
\text { partum week }\end{array}$ & & $\begin{array}{l}\text { Ef- } \\
43 \%\end{array}$ & $\begin{array}{l}\text { LSCS } \\
\text { (CPD) }\end{array}$ & $\begin{array}{l}\text { Digoxin } \\
\text { Lasilactone } \\
\text { Ivabrad } \\
\text { Cardace } \\
\text { Carvidilol }\end{array}$ & 5days \\
\hline
\end{tabular}

Table 5: Clinical profile of women with PPCM in previous pregnancy four cases.

\begin{tabular}{|c|c|c|c|c|c|c|c|}
\hline Cases & $\begin{array}{l}\text { Age } \\
\text { (yrs) }\end{array}$ & $\begin{array}{l}\text { Obstetric } \\
\text { score }\end{array}$ & Obstetric history & $\begin{array}{l}\text { Gest. } \\
\text { age }\end{array}$ & Complications & Procedure & Echo - EF \\
\hline 1 & 30 & $\begin{array}{l}\text { G3 P1 L1 } \\
\text { A1 }\end{array}$ & $\begin{array}{l}\text { G1 - LSCS at term, } \\
\text { IND: PPCM + G2 - } \\
\text { Sp Abortion at } 2 \\
\text { months }\end{array}$ & 38 wks & $\begin{array}{l}\text { Electrical } \\
\text { instability - } \\
\text { BIGEMINY }\end{array}$ & $\begin{array}{l}\text { Emergency } \\
\mathrm{LSCS}+\mathrm{B} / \mathrm{L} \\
\text { tubectomy }\end{array}$ & $\begin{array}{l}\text { EF- } 60 \% \\
\text { FREQUENT } \\
\text { ECTOPICS - } \\
\text { BIGEMINY }\end{array}$ \\
\hline 2 & 24 & G3P1L1A1 & $\begin{array}{l}\text { G1-LSCS at term, } \\
\text { IND: CPD PPCM } 4 \\
\text { months after delivery } \\
\text { G2-Sp abortion }\end{array}$ & 39 wks & & $\begin{array}{l}\mathrm{LSCS}+\mathrm{B} / \mathrm{L} \\
\text { tubectomy }\end{array}$ & EF-70\% \\
\hline 3 & 23 & G2P1L1 & $\begin{array}{l}\text { G1-VD. PPCM after } \\
\text { delivery }\end{array}$ & 9 wks & $\begin{array}{l}\text { Mild LV } \\
\text { dysfunction }\end{array}$ & $\begin{array}{l}\text { Suction and } \\
\text { evacuation }\end{array}$ & EF-45\% \\
\hline 4 & 26 & G3P2L2 & $\begin{array}{l}\text { GI-VD } \\
\text { G2-VD, PPCM after } \\
\text { delivery } \\
\text { G3-PP. Referred here } \\
\text { at 39wks }\end{array}$ & 39 wks & & $\begin{array}{l}\mathrm{LSCS}+\mathrm{B} / \mathrm{L} \\
\text { tubectomy } \\
\text { IND: breech }\end{array}$ & EF-64\% \\
\hline
\end{tabular}

\section{Drug management}

Adequate control of hypertension was achieved with Methyl dopa, Labetalol and Calcium channel blockers.
Magnesium sulphate was given as per protocol to prevent convulsions in imminent eclampsia and severe preeclampsia. Ionotropic drugs like levosimendan and dobutamine were used in patients in NYHA Class 4 and 
not recovering from failure. Diuretics are used to decrease volume load.

Drugs like aldactone are contraindicated in pregnant women but can be started in the post-partum period. These women need specialist advice during lactation.

\section{Duration of ICU stay and hospital stay}

This data is for the six women who had PPCM in relation to the present pregnancy. Two women were admitted and managed in HDU. Four had a total hospital stay and ICU stay of, $11 / 4,6 / 5,10 / 8,8 / 5$ days.

\section{Mode of delivery}

The three women diagnosed with PPCM prior to delivery, were delivered by caesarean section. The other three who were diagnosed with PPCM in the post-partum period, the mode of delivery was tailored to their obstetric condition.

\section{In the four women with PPCM in the previous pregnancy}

One woman had termination of pregnancy at 9 weeks, the rest of the three had an elective abdominal delivery. Table 5 clinical profile of women with PPCM in previous pregnancy four cases.

\section{Pregnancy termination}

One woman had termination of pregnancy at 9 weeks, as per the cardiologists advise. G2P1L1, 23 years, presented to us at 9 weeks pregnancy. She developed PPCM after her first delivery in the immediate postpartum period. In this pregnancy, she had an ejection fraction of $45 \%$ and mild LV dysfunction on assessment. She had a medically indicated surgical evacuation of pregnancy.

\section{Perinatal outcome}

There was no perinatal mortality in the 9 cases who delivered.

\section{Maternal outcome}

There was no maternal mortality in the 11 cases described.

\section{Case 11, rare presentation}

Mrs. M, 26 years, was referred to care institute of medical sciences as a case of ruptured ectopic pregnancy in shock. G2 P1 L1 with 8 weeks gestation, with PR126/min, BP- 60/00 $\mathrm{mm} \mathrm{Hg}$. On examination P/Aabdomen was distended, suprapubic scar was noted of previous caesarean section. Tenderness on palpation of the abdomen was noted.
Laparotomy was done under GA (general anesthesia), left salpingectomy was done for ruptured tubal pregnancy. Almost 3.5 litres of hemoperitoneum was noted. Transfusion of 4 units whole blood, 2 PRBC, 4 FFP was done. Serosanguinous fluid was draining from the abdominal drain, $765 \mathrm{ml}, 10$ hours after surgery. A 2DECHO was performed when hemodynamic instability continued and the findings were, EF- 30\%, severe LV dysfunction, severe global hypokinesia, restrictive LV filling pattern.

Ionotropic support continued with norepinephrine, dobutamine and she was managed with drugs, digoxin, aldactone, frusemide, IV levosimendan infusion- 2.5 $\mathrm{mg}$ /hour for 4 hours. Her total hospital stay was 15 days and ICU stay were for 13 days. Echo at discharge, EF$66 \%$, altered LV compliance. She was advised follow up, was advised against immediate conception.

\section{DISCUSSION}

Peripartum cardiomyopathy is a rare form of cardiomyopathy presenting in late pregnancy and postpartum. It is associated with high maternal morbidity and mortality. There are associated fetal complications like premature delivery and still births.

\section{Age}

The incidence of PPCM is strongly associated with age. Even though the disease can strike women of any age, $>50 \%$ of cases occur in women $>30$ years of age, with an odds ratio of 10 in a comparison of women $>40$ and $<20$ years of age. 2,6,11,12 PPCM occurs slightly early in Indian women as described earlier by Gowri et. al. ${ }^{13}$ Marriage at early age and early parity may contribute to early PPCM in Indian studies. The primies who were included in our study also were young with age range of 21 to 27 years.

\section{HTN, PE and PPCM}

HTN was present in $66.6 \%$ (4/6) patients in our study with $50 \%$ (3/6) having preeclampsia with PPCM and one HELPP syndrome. A meta-analysis of pooled data from 22 studies showed preeclampsia, HTN (Hypertension) and PPCM to be closely related. Prevalence of PPCM is higher in patients with PE (pre-eclampsia) and Hypertension than in general population. PE is associated with pulmonary edema, but systolic function is normal in this group of patients. There is increased incidence of PE in women with PPCM but more than $90 \%$ of women with PE do not develop PPCM. In view of relation between the two, vascular pathologies have been proposed as an etiology for PPCM. The study in rural Haiti concluded that reason for PE and PPCM may be different in that population.

\section{Multidisciplinary approach}

In our study all patients were managed by pregnancy cardiac team including cardiologist, obstetrician, 
neonatologist and intensivist. In women with a moderate or high-risk of complications during pregnancy (mWHO II-III, III, and IV), pre-pregnancy counselling and management during pregnancy and delivery should be conducted in an expert center by a multidisciplinary team. ${ }^{14}$

\section{Early diagnosis of PPCM}

In our study $6(54.5 \%)$ patients presented early, $3(50 \%)$ of the patients recovered, while $3(50 \%)$ patients did not have any improvement in LVEF. One patient presenting later with symptom, onset at 10 weeks postpartum recovered from heart failure symptoms but continued to have dilated ventricle and low EF on follow up.

Studies have suggested that earlier diagnosis and small ventricular sizes have better prognosis. In a retrospective study it was demonstrated that PPCM is diagnosed later in women in underserved populations, which correlates with worse outcomes. This study suggests that earlier PPCM diagnosis among other clinical determinants may be a key to recovery. ${ }^{15}$

\section{Establishing a diagnosis of PPCM}

In our series $7(63.6 \%)$ presented with heart failure, 5 (45\%) with exertional breathlessness, 2 (18\%) with pedal oedema and $1(9 \%)$ with syncope. Nearly half $(54 \%)$ patients had sinus tachycardia at presentation and one patient had PVCs. 5 (45\%) patients were in NYHA class 4, 1 in class 3 and 5 in class 2.4 patients with asymptomatic cardiac status had PPCM in previous pregnancy as per the old records. Their data during the PPCM could not be obtained (Table 3).

Many patients of PPCM have symptoms common to normal pregnancy. Gynecologists and general physicians should have an awareness of disease. Early ECG, echocardiogram and biomarkers like BNP (brain naturitic peptide) and TROP T will help to make a diagnosis. An early referral to a pregnancy cardiac team is associated with better prognosis. ${ }^{15-18}$ Delayed presentation and diagnosis are associated with bad prognosis. A validated self-test helps in early diagnosis of PPCM. Term pregnancy may have signs and symptoms similar to early heart failure symptoms. Because PPCM is an uncommon disease many women and their physicians may consider some of these symptoms and signs to be a normal part of pregnancy. This lends emphasis to the need for discriminating between the two. In their study the most common symptoms or signs of heart failure were identified. ${ }^{17}$ Each of the 6 components of the self-test was quantified in easily understood categories for selfscoring. A score greater than 4 points indicated a need for further evaluation. The authors are of opinion that this validation process has been associated with early diagnosis of left ventricular systolic dysfunction.

\section{Medical management}

Assessment of a patient by both NYHA criteria and WHO classification of pregnancy helps in better assessment of PPCM patients. ${ }^{15}$

NYHA classification takes into consideration of cardiac status alone while mWHO classification includes functional status and LVEF hence may be a better indicator of prognostication. It guides in predicting maternal mortality and in planning of management of high-risk pregnancies and counselling regarding repeat pregnancies, which is an important component of management of PPCM.

In women with a moderate or high-risk of complications during pregnancy (mWHO II-III, III, and IV), prepregnancy counselling and management during pregnancy and around delivery should be conducted in an expert center by a multidisciplinary team, the pregnancy heart team. The minimum team requirements are a cardiologist, obstetrician, and anesthetist, all with expertise in the management of high-risk pregnancies in women with heart disease. Additional experts that may be involved depending on the individual situation, are a geneticist, cardiothoracic surgeon, pediatric cardiologist, foetal medicine specialist, neonatologist, hematologist, nurse specialist, pulmonary specialist, and others where appropriate. In this team patients from other centers can also be discussed, so not every hospital needs to have its own pregnancy heart team. The conclusions and recommendations should be filed and made available 24 $\mathrm{h}$ per day.

\section{Management of heart failure in PPCM}

The principles of managing heart failure related to PPCM are extrapolated from data similar to other conditions with heart failure. ${ }^{18}$ Salt restriction and volume status management are essential, and patients' need to be educated by a cardiologist or nurse trained in heart failure management. Neuro humoral blockade with ace inhibitor and beta blockers are main principles of therapy as in other forms of heart failure with reduced EF. Nitrates and hydralazine are preferred instead of ACEI in preterm pregnant women with PPCM.

Adequate control of hypertension is achieved with methyl dopa, labetalol and calcium channel blockers.

Ionotropic drugs like levosimendan and dobutamine are used in patients in NYHA Class 4 and not recovering from failure. Diuretics are used to decrease volume load.

Drugs like Aldactone are contraindicated in pregnant women but can be started in post-partum period. These women need specialist advice during lactation. Role of digoxin in heart failure in patient without atrial fibrillation is controversial. 
In our center heart failure management was standardized by cardiologists who manage ICCU. In our study betablockers were used in $6(54.5 \%)$ patients, 4 normotensives received metoprolol, 2 hypertensives received labetalol and one patient received carvedilol. Ivabradine was used for rate control in 4 (36.3\%) patients where betablocker was contraindicated. ACE inhibitor was received by $3(27.2 \%)$ patients. One $(9 \%)$ patient in shock required levosimendan and one $(9 \%)$ patient in refractory heart failure was given Digoxin along with ACI and diuretics.

\section{Anesthetic management and obstetric management}

Type of delivery and timing of delivery are decided by obstetric indication and patient's wishes. Randomized control trials are not available for timing and type of delivery. Anesthetic management depends on hemodynamic status, NYHA class, WHO status, tachycardia, arrythmia of the patient and time of presentation. ${ }^{19}$ Patients without hemodynamic instability can be observed and do not require emergency LSCS. Fetal status should be assessed clinically and by ultrasound in those stable patients where delivery is awaited.

Pain and anxiety are associated with tachycardia resulting in worsening LV function. Increase in PVR results in after load increase on already failing heart. Sympathetic overflow results in reduced uteroplacental flow compromising the fetus.

Urgent delivery, irrespective of gestation, may need to be considered in women presenting or remaining in advanced HF with hemodynamic instability. Planned Caesarean section is preferred for women who are critically ill and in need of inotropic therapy or mechanical support. ${ }^{20}$ In general vaginal delivery is encouraged. ${ }^{10}$ Cardiovascular challenges during labor and delivery include supine hypotension, increased cardiac output, blood loss, and judicious administration of intravenous fluids.

\section{Effective labour analgesia}

Patients should be monitored during vaginal delivery and adequate analgesia should be provided. Second stage is to be shortened with forceps delivery. Patients depending on the hemodynamic status and WHO class apart from obstetric indication may need LSCS. LSCS can be done under GA or EA (Epidural anesthesia). Regional anesthesia is contraindicated in anticoagulated patients.

One out of 11 of our patients underwent vaginal delivery and eight $(72.7 \%)$ patients underwent LSCS. Indication for LSCS was CPD (cephalo pelvic disproportion) in 3 $(27 \%)$ and previous LSCS in $5(45 \%)$. One patient with ectopic pregnancy and cardiogenic shock underwent laparotomy and one patient underwent therapeutic abortion.

\section{Predictors of recovery}

LVEF and LV size at presentation remained major predictors of recovery. In view of rarity of disease and lack of randomized trials, factors determining recovery are not very well identified. IPAC group of investigators did a univariate and multivariate analysis of PPCM patients after one year of follow-up. They found that $72 \%$ of women had complete event free survival. Out comes were significantly worse for women with $\mathrm{LVEF}<30 \%$ compared to women with $\mathrm{LV} \mathrm{EF}>30 \%$ with one-year event free survival rate of $82 \%$ versus $92 \%$ ( $p=0.004)$. In a multivariate analysis race and LVEDD remained significant predictors of LVEF at 12 months. ${ }^{21}$

In our study $3 / 6(50 \%)$ patients and patient presenting with ectopic pregnancy recovered to EF more than $50 \%$. Rest of $3(50 \%)$ patients remained with LVEF <45\%. In patients with history of previous PPCM $3 / 4 \quad(75 \%)$ recovered while one patient remained with $\mathrm{LVEF}<45 \%$.

\section{Delayed recovery}

Persistence of LV dysfunction defined as EF of $<50 \%$ at $>6$ months is a marker of irreversible PPCM. ${ }^{22}$ These patients tend to require advanced therapies for their heart failure like CRT, LVAD and transplantation.

\section{Recurrence with subsequent pregnancy}

In our study 4 patients had history of PPCM in previous delivery. Three of $4(75 \%)$ had LVEF $>50 \%$ (with a mean of $64.5 \%$ ). All three of them were delivered by LSCS. One patient $(25 \%)$ with LVEF of $<45 \%$ underwent therapeutic abortion at 9 weeks gestation.

In Patients with history of PPCM, LVEF increased during index pregnancy but decreased again during the subsequent pregnancy, irrespective of earlier values. ${ }^{23}$ Heart failure was more frequent in those in whom LVEF has not normalized. Deaths were reported in women with persistently low LVEF entering the subsequent pregnancy, whereas none with normalized LVEF died. There was no perinatal mortality. There was higher incidence of premature delivery and therapeutic abortions. In a retrospective study which compared 70 patients with PPCM, 21 had a successful subsequent pregnancy, pregnancy terminated in 16, and the remaining 33 had no subsequent pregnancy. Ejection fraction at diagnosis was higher in those who had a successful subsequent pregnancy, but one third of the patients had worsening symptoms in subsequent pregnancy. ${ }^{21,24}$

\section{Unusual presentation}

26 years lady in shock was referred as a case of ruptured ectopic pregnancy. After instituting hemodynamic stability, laparotomy was done under general anaesthesia and left salpingectomy was done for ruptured tubal 
pregnancy. A 2D-Echo was performed as hemodynamic instability continued and was found to have severe ventricular dysfunction. She recovered her LV function at the time of discharge.

Cases which are described at this early period of gestation are uncommon. Two studies in literature have described PPCM as early as during first month of pregnancy. ${ }^{25,26}$ The unusual feature about this patient was very early presentation in the 8th week of pregnancy. This patient presented in cardiogenic shock with severe LV dysfunction. She recovered with ionotropic support and heart failure therapy. A very likely differential diagnosis is stress cardiomyopathy, however echocardiographic features did not suggest a typical apical ballooning syndrome or stress cardiomyopathy. We could not find any references in literature for PPCM in ectopic pregnancy. Hence this case is being classified as a PPCM and added to this series.

\section{Limitations}

Small number of patients were in the study.

\section{CONCLUSION}

PPCM is a rare condition. It requires a high index of suspicion and awareness among primary care givers for early diagnosis and prompt management. A pregnancy cardiac team approach benefits this subset of patients. Delayed time of presentation, LVEF and dilated ventricle are factors determining recovery.

Funding: No funding sources

Conflict of interest: None declared

Ethical approval: The study was approved by the Institutional Ethics Committee

\section{REFERENCES}

1. Demakis JG, Rahimtoola SH, Sutton GC, Meadows WR, Szanto PB, Tobin JR, Gunna RM. Natural course of peripartum cardiomyopathy. Circulation. 1971;44(6):1053-61.

2. Mielniczuk LM, Williams K, Davis DR, et al. Frequency of peripartum cardiomyopathy. Am J Cardiol. 2006;97:1765-8.

3. The Relationship Between Preeclampsia and Peripartum Cardiomyopathy: A Systematic Review and Meta-Analysis Natalie Bello, MD, Iliana S. Hurtado Rendon, MD, and Zoltan Arany, MD, PhDAm Coll Cardiol. 2013;62(18):1715-23.

4. Fett JD, Christie LG, Carraway RD. Five-year prospective study of the incidence and prognosis of peripartum cardiomyopathy at a single institution. Mayo Clin Proc. 2005;80:1602-6.

5. Sliwa K, Förster O, Libhaber E, Fett JD, Sundstrom JB, Hilfiker-Kleiner D, et al. Peripartum cardiomyopathy: inflammatory markers as predictors of outcome in 100 prospectively studied patients. Europ Heart J. 2006;27(4):441-6.

6. Brar SS, Khan SS, Sandhu GK, Jorgensen MB, Parikh N, Hsu JW, Shen AY. Incidence, mortality, and racial differences in peripartum cardiomyopathy. Am J Cardiol. 2007;100(2):302-4.

7. Harper MA, Meyer RE, Berg CJ. Peripartum cardiomyopathy: population-based birth prevalence and 7-year mortality. Obstet Gynecol. 2012;120:1013-9.

8. Krishnamoorthy P, Garg J, Palaniswamy C, Pandey A, Ahmad H, Frishman WH, et al. Epidemiology and outcomes of peripartum cardiomyopathy in the United States: findings from the Nationwide Inpatient Sample. J Cardiovasc Med. 2016;17(10):756-61.

9. Pearson GD, Veille JC, Rahimtoola S, Hsia J, Oakley CM, Hosenpud JD, Ansari A, Baughman KL. Peripartum cardiomyopathy: national heart, lung, and blood institute and office of rare diseases (National Institutes of Health) workshop recommendations and review. J Am Medic Assoc. 2000;283(9):1183-8.

10. Sliwa K, Hilfiker-Kleiner D, Petrie MC, Mebazaa A, Pieske B, Buchmann E, et al. Current state of knowledge on aetiology, diagnosis, management, and therapy of peripartum cardiomyopathy: a position statement from the Heart Failure Association of the European Society of Cardiology Working Group on peripartum cardiomyopathy. Europ J Hea Fail. 2010;12(8):767-78.

11. Gunderson EP, Croen LA, Chiang V, Yoshida CK, Walton D, Go AS. Epidemiology of peripartum cardiomyopathy: incidence, predic- tors, and outcomes. Obstet Gynecol. 2011;118:583-91.

12. Kolte D, Khera S, Aronow WS, Palaniswamy C, Mujib M, Ahn C, et al. Temporal trends in incidence and outcomes of peripartum cardiomyopathy in the United States: a nationwide population-based study. J Am Heart Assoc. 2014;3:e001056.

13. Prasad GS, Bhupali A, Prasad S, Patil AN, Deka Y. Peripartum cardiomyopathy-case series. Ind Hea J. 2014;66(2):223-6.

14. ESC Guidelines on the management of cardiovascular diseases during pregnancy The Task Force on the Management of Cardiovascular Diseases during Pregnancy of the European Society of Cardiology (ESC). Europ Hea J. 2011;32:3147-97.

15. Lewey J, Levine LD, Elovitz MA, Irizarry O, Arany Z. The impor- tance of early diagnosis in peripartum cardiomyopathy. Hypertension. 2019;74.

16. Multidisciplinary management of peripartum cardiomyopathy during repeat cesarean delivery: a case report Janice Shannon-Cain 1, Eric Hunt, Brian S Cain AANA J. 2008;76(6):443-7.

17. Fett JD. Validation of a self-test for early diagnosis of heart failure in peripartum cardiomyopathy. Crit Pathw Cardiol. 2011;10(1):44-5.

18. ACCF/AHA Guideline for the Management of Heart Failure A Report of the American College of 
Cardiology Foundation/ American Heart Association Task Force on Practice Guidelines 2013;62:16.

19. Ramachandran R, Rewari V, Trikha A. Anaesthetic management of patients with Peripartum Cardiomyopathy. J Obstet Anaesth Crit Care. 2011:5-12

20. Dinic V, Markovic D, Savic N, Kutlesic M, Jankovic RJ. Peripartum cardiomyopathy in intensive care unit: an update. Front Medic. 2015;2:82.

21. McNamara DM, Elkayam U, Alharethi R, Damp J, Hsich E, Ewald G. Clinical Outcomes for Peripartum Cardiomyopathy in North America: Results of the IPAC Study (Investigations of Pregnancy-Associated Cardiomyopathy). J Am Coll Cardiol. 2015;66(8):905-14.

22. Biteker M, Ilhan E, Biteker G, Duman D, Bozkurt B. Delayed recovery in peripartum cardiomyopathy: an indication for long-term follow-up and sustained therapy. Eur J Heart Fail. 2012;14(8):895-901.

23. Elkayam U, Tummala PP, Rao K, Akhter MW, Karaalp IS, Wani OR, et al. Maternal and fetal outcomes of subsequent pregnancies in women with peripartum cardiomyopathy. $\mathrm{N}$ Engl $\mathrm{J}$ Med 2001;344:1567-71.

24. Habli M, O'Brien T, Nowack E, Khoury S, Barton JR, Sibai B. Peripartum cardiomyopathy: prognostic factors for long-term maternal outcome. Am J Obstet Gynecol. 2008;199(4):415-e1.

25. Elkayam U, Akhter MW, Singh H, Khan S, Bitar F, Hameed A, et al. Pregnancy-associated cardiomyopathy: clinical characteristics and a comparison between early and late presentation. Circulation. 2005;111(16):2050-5.

26. Wu VC, Chen TH, Yeh JK, Wu M, Lu CH, Chen $\mathrm{SW}$, et al. Clinical outcomes of peripartum cardiomyopathy: a 15-year nationwide populationbased study in Asia. Medicine. 2017;96(43).

Cite this article as: Devabhaktuni $\mathrm{P}$, Chennapragada S, Manchala S, Menon R, Patil N, Bhupatiraju S.

Peripartum cardiomyopathy managementmultidisciplinary approach 2011-2013 at Care Institute of Medical Sciences. 2011-2013 at CIMS. Int J Reprod Contracept Obstet Gynecol 2020;9:4883-91. 